\title{
MANUFACTURE AND PROPERTY EVALUATION OF SUPER ALLOY 44NI-14CR-1.8NB-1.7TI-1.5MO-0.3V-FE ( MODIFIED 706 ) -AN EXPERIENCE
}

\author{
U V Gururaja, P Sarkar, M Narayana Rao, \\ Mishra Dhatu Nigam Limited, HYDERABAD, INDIA.
}

Keywords: Alloy 706, Modified Alloy 706.

\begin{abstract}
The alloy $44 \mathrm{Ni}-14 \mathrm{Cr}-2.6 \mathrm{Nb}-1.7 \mathrm{Ti}-1.5 \mathrm{Mo}-0.3 \mathrm{~V}-\mathrm{Fe}$ is derived from the family of super alloys 706 and 718 compositions. It is a precipitation hardenable alloy with its primary constituents consisting of Niobium and Titanium. A balanced content of Nickel, Chromium and Aluminium in alloy 706 provides good hardenability and resistance against oxidation and corrosion. Further modified 706 with Molybdenum and Vanadium improve its high temperature capabilities. Modified 706 displays excellent mechanical properties in combination with good fabricability compared to structurally complex 718. This alloy finds application in aerospace field requiring high strength and ease of fabrication. The present paper describes the manufacturing practice adopted and presents mechanical properties evaluated on various products.
\end{abstract}

\section{Introduction}

Modified 706 belongs to Ni-Fe base super alloys. Ni-Fe base super alloys are age-hardenable by the precipitation of coherent $\gamma^{\prime}$ and /or $\gamma^{\prime}$ in the austenitic matrix $\gamma$ (1). Alloy 706 was developed from Alloy 718, a representative wrought super alloy. Compared with Alloy 718, Alloy 706 has a chemical composition with no molybdenum, reduced niobium, aluminium, chromium, nickel, carbon and increased Titanium and Iron. A further study on modification to 706 chemistry for advanced USC power plants is under progress (2-5). In modified 706 of present work, an alloy in use else where, for which no published literature is available, molybdenum and Vanadium are added.

The excellent balance of these elements in modified 706 results in superior characteristics to Alloy 718 in segregation tendency, hot workability and enhances response thickness of product for heat treatment. Hence modified 706 is suitable for large forgings and high temperature services. This paper describes the manufacturing route adopted for production and properties obtained on various products of modified 706 in comparison to Alloy 718 \& 706. 


\section{Experimental Procedure}

The Alloy 718, 706 and modified 706 used in this study are primarily melted in a VIM furnace. Further remelted by Vacuum arc remelting to produce ingots of diameter $400 \mathrm{~mm}$. These remelted ingots have under gone different heating and thermo mechanical processing steps to produce various forged products. The chemical composition of the alloys used in this study are presented at Table 1. It is a well established fact that Alloy 718 is highly segregation prone during melting and remelting due to high niobium content in the alloy. Alloy 706 and modified 706 the percentage of Niobium has been reduced considerably and because of which ingots can

Table-1. Chemical compositions of Alloys

\begin{tabular}{|l|l|l|l|l|l|l|l|l|l|l|l|l|l|}
\hline Alloy & $\mathrm{C}$ & $\mathrm{S}$ & $\mathrm{P}$ & $\mathrm{Mn}$ & $\mathrm{Si}$ & $\mathrm{Cr}$ & $\mathrm{Ni}$ & $\mathrm{Mo}$ & $\mathrm{Al}$ & $\mathrm{Ti}$ & $\mathrm{Nb}$ & $\mathrm{Fe}$ & Others \\
\hline 718 & 0.02 & 0.002 & 0.005 & 0.02 & 0.01 & 18.0 & 52.8 & 2.92 & 0.52 & 1.01 & 5.21 & $\mathrm{Bal}$ & $0.004 \mathrm{~B}$ \\
\hline 706 & 0.044 & 0.001 & 0.005 & 0.05 & 0.01 & 15.78 & 40.4 & -- & 0.24 & 1.67 & 2.93 & $\mathrm{Bal}$ & $0.006 \mathrm{~B}$ \\
\hline $\begin{array}{l}\text { Modified } \\
706\end{array}$ & 0.05 & 0.001 & 0.006 & 0.06 & 0.06 & 13.81 & 43.5 & 1.56 & 0.53 & 1.87 & 2.60 & $\mathrm{Bal}$ & $\begin{array}{l}\mathrm{V}: 0.30 \\
\mathrm{~B}: 0.0045\end{array}$ \\
\hline
\end{tabular}

be produced comfortably without any freckle formation problems. Modified 706 alloy is easily forgeable compared to Alloy 718. Press and furnace time requirements are considerably less to that of alloy 718 . Ingots were forged from $400 \mathrm{~mm}$ to different size products. Products were subjected to a solution treatment in the range of 925 to $1010^{\circ} \mathrm{C}$ followed by double ageing at $720^{\circ} \mathrm{C}$ for $8 \mathrm{hrs}$ furnace cool to $620^{\circ} \mathrm{C}$ in $2 \mathrm{hr}$ and kept at $620^{\circ} \mathrm{C}$ for $8 \mathrm{hr}$, a cycle that is similar to Alloy 718. The products were evaluated for macro, micro and mechanical properties. Macro structure obtained on a 100mm thick slab is given at Figure-1. Microstructure obtained at optical level at 100X and 500X are shown at Figure-2. Further study carried out using SEM in solution annealed and aged condition is given at Figure-3. Semi quantitative EDAX analysis is presented at Figure-4. Alloy modified 706 contains about $0.3 \%$ by weight Vanadium, since EDAX is insensitive for less than $1 \%$ by weight elemental analysis, Vanadium is not figured in the report at Figure-4.

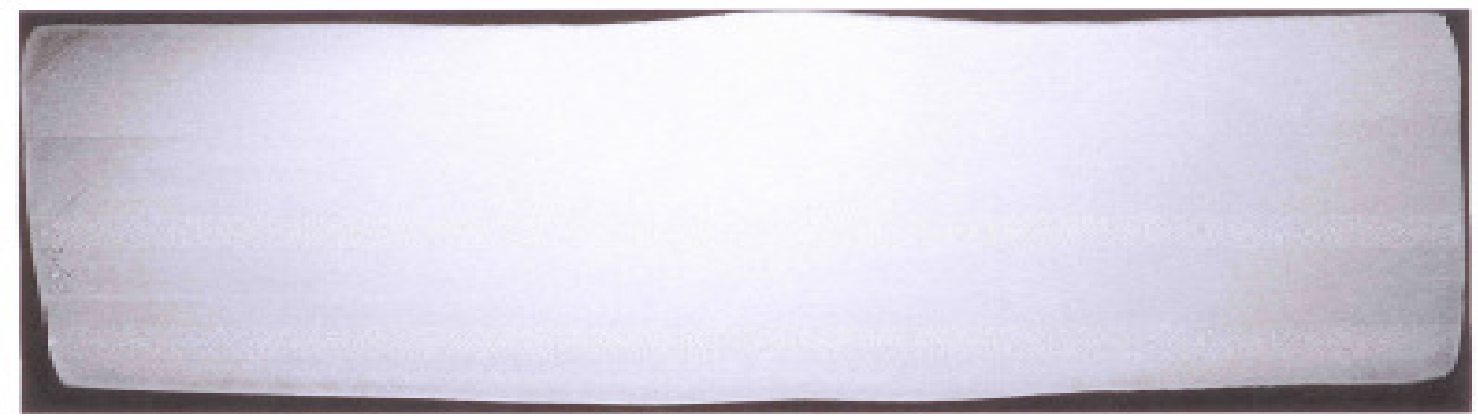

Figure-1: Macro photograph of 100x350mm slab of Modified Alloy 706 

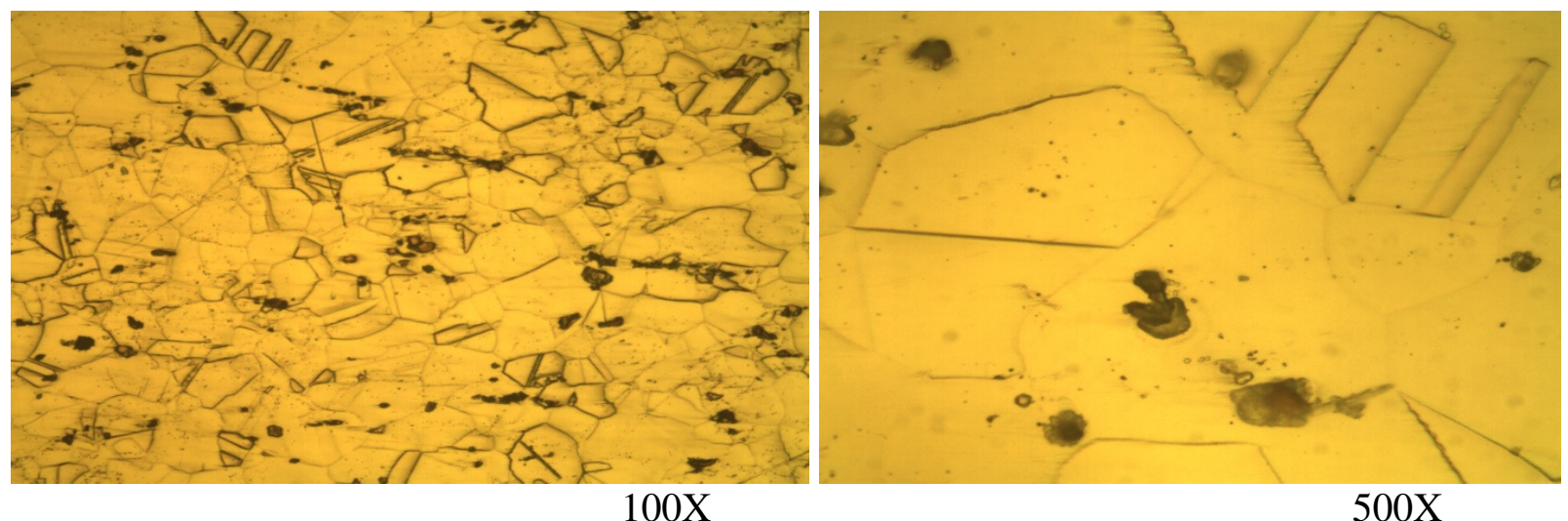

Figure-2 : Optical photo micrographs of Modified Alloy 706

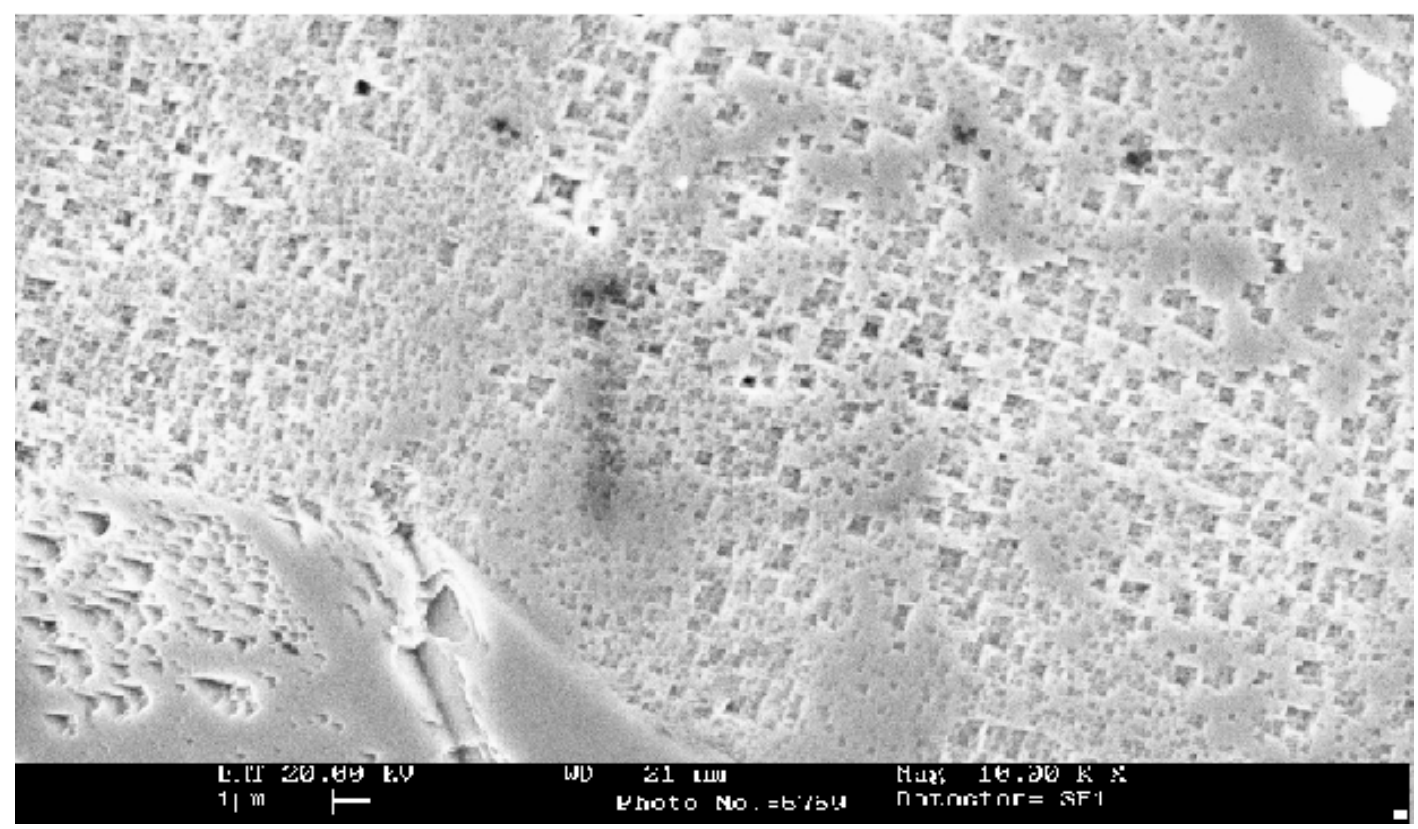

Figure-3: SEM micrograph of Modified Alloy 706 in aged condition.

\begin{tabular}{cccc} 
Elmt & \multicolumn{3}{c}{ Spect. Element } \\
& Type & $\%$ & $\%$ \\
Al K & ED & 0.54 & 1.14 \\
Ti K & ED & 2.14 & 2.55 \\
Cr K & ED & 13.62 & 14.93 \\
Fe K & ED & 35.50 & 36.23 \\
Ni K & ED & 43.64 & 42.37 \\
Nb L & ED & 3.21 & 1.97 \\
Mo L & ED & 1.34 & 0.80 \\
Total & \multicolumn{2}{c}{100.00} & 100.00
\end{tabular}

Figure-4: EDAX analysis of Modified Alloy 706. 


\section{Results \& Discussion}

It is evident from the macro photograph and study on a number of production heats, modified Alloy 706 is not prone to macro segregation problems like white spots and freckles akin to super alloys. Alloy 706 is evolved from the development of Alloy 718 to satisfy metallurgical requirements for large forged gas turbine components (6). Nickel, Molybdenum and hardner content were lowered to enhance forgeability, reduce the tendency of the alloy range to develop macro segregation in large cross sections, improve machinability and lower cost. Niobium and Aluminum content were also reduced to decrease the tendency for segregation and freckle formation. The reduction of these hardeners necessitated an increase in the Titanium contenet to maintain the alloys strength characteristics. Further, in modified 706, Molybdenum is added and Aluminum is kept slightly on higher side and micro alloying of Vanadium is also done.Figure-2 shows the typical microstructure of modified Alloy 706. The microstructure reveals austenitic grains with annealing twins, a few MC type carbides. Table- 2 displays the major phases and typical morphologies found in Alloy 706 (7).

Table 2: Major Precipitating Phases Present in Alloy 706 (7)

\begin{tabular}{|c|c|c|c|}
\hline Precipitating Phase & Structure & Morphology & Composition \\
\hline$\gamma$ & Ordered FCC & Spheres & $\mathbf{N i}_{3}(\mathbf{A l}, \mathbf{T i})$ \\
\hline$\gamma^{\prime}$ & Ordered BCT & Disks & $\mathbf{N i}_{3} \mathbf{N b}$ \\
\hline Laves & HCP & Globular & $(\mathbf{F e}, \mathbf{N i})_{2} \mathbf{N b}$ \\
\hline$\eta$ & HCP & Platelets / Cellular & $\mathbf{N i}_{3} \mathbf{T i}$ \\
\hline$\delta$ & Orthorhombic & Needles & $\mathbf{N i}_{3} \mathbf{N b}$ \\
\hline
\end{tabular}

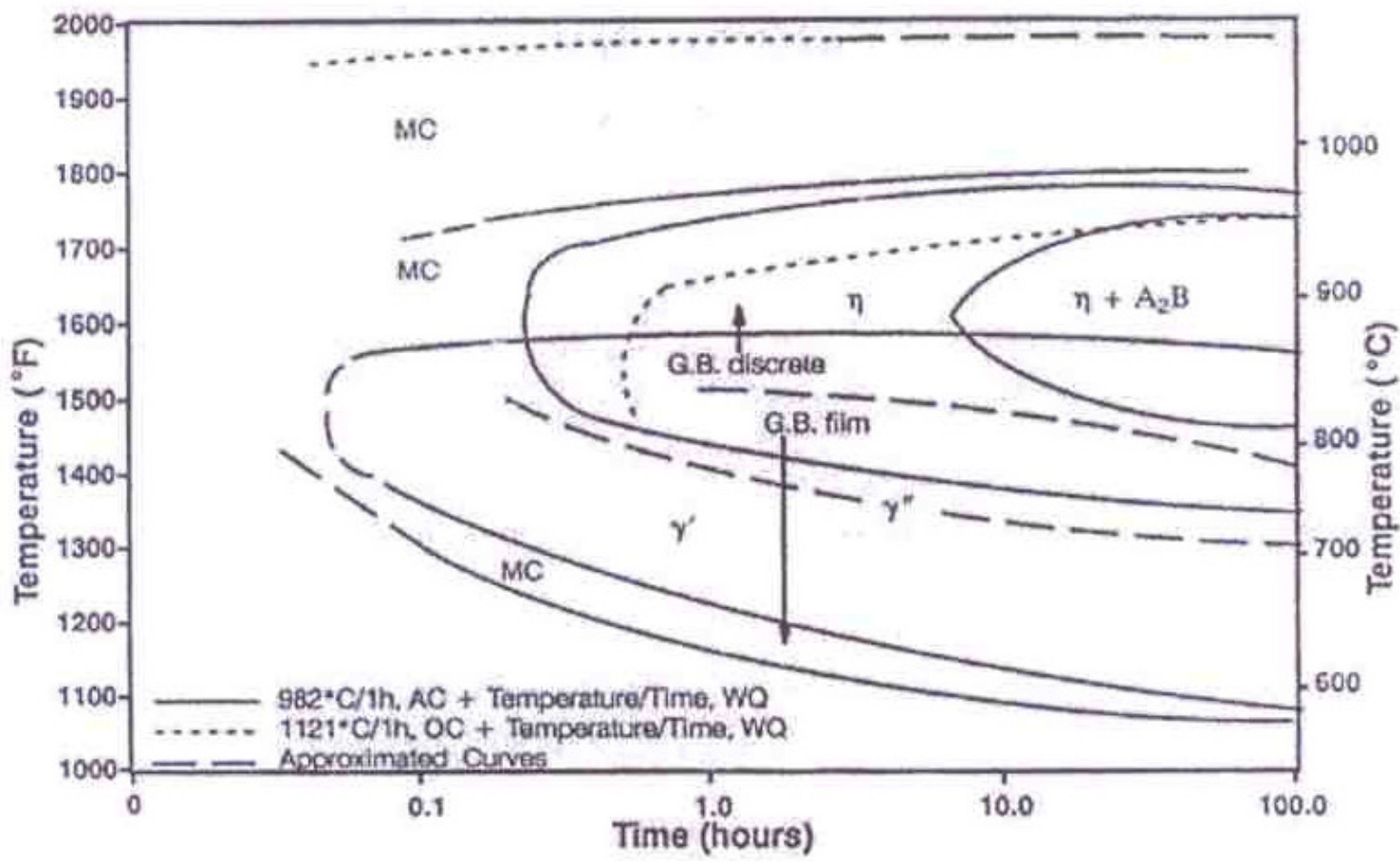

Figure-5: Approximate Time - Temperature - Transformation Diagram for Alloy 706 (8) 
Figure-5 shows the TTT diagram for Alloy 706 developed by Heck (8). It will be a useful guide in predicting the transformation phases that are expected in modified Alloy 706. SEM

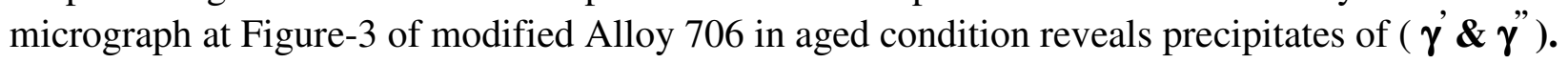
The alloy is yet to be characterized completely for its micro-structural features. Like Alloy 706, modified Alloy 706 is also used in solution treated and aged condition. The heat treatments for this type of super alloy are generally classified as tensile specific or creep / stress rupture specific. In this present study only tensile specific heat treatment was given. The alloy is yet to be evaluated for its creep and stress rupture capabilities. Properties evaluated on products of Alloy 718 alloy 706 and modified 706 are presented at Table2. High temperature tensile properties of modified 706 are presented at Table- 3.

Table 2: Tensile Properties of Forged bars of Alloy 718, Alloy 706 and Modified 706

\begin{tabular}{|l|l|l|l|l|l|l|}
\hline Alloy & Product & $\begin{array}{l}0.2 \% \text { YS } \\
(\mathrm{MPa})\end{array}$ & $\begin{array}{l}\text { UTS } \\
(\mathrm{MPa})\end{array}$ & $\%$ EL & $\%$ RA & Grain size \\
\hline 718 & $\begin{array}{l}100 \mathrm{~mm} \text { thick } \\
\text { slab }\end{array}$ & 1126 & 1384 & 21 & 32 & ASTMNo.5 \\
\hline 706 & $\begin{array}{l}\text { Dia } 125 \mathrm{~mm} \\
\text { bar }\end{array}$ & 780 & 890 & 17 & 34 & ASTMNo.5 \\
\hline $\begin{array}{l}\text { Modified } \\
706\end{array}$ & $\begin{array}{l}100 \mathrm{~mm} \text { thick } \\
\text { slab }\end{array}$ & 819 & 1174 & 25 & 34 & ASTMNo.5 \\
\hline $\begin{array}{l}\text { Modified } \\
706\end{array}$ & $\begin{array}{l}6 \mathrm{~mm} \\
\text { thick Plate }\end{array}$ & 862 & 1271 & 23 & -- & $\begin{array}{l}\text { ASTM No } \\
5 \& 6\end{array}$ \\
\hline
\end{tabular}

Table -3 High temperature tensile properties of Modified 706

\begin{tabular}{|l|l|l|l|l|l|}
\hline Product & $\begin{array}{l}\text { Test } \\
\text { Temperature }\end{array}$ & $\begin{array}{l}0.2 \% \text { YS } \\
(\mathrm{MPa})\end{array}$ & $\begin{array}{l}\text { UTS } \\
(\mathrm{MPa})\end{array}$ & $\%$ EL & Grain size \\
\hline $100 \mathrm{~mm}$ thick & $100^{\circ} \mathrm{C}$ & 830 & 1142 & 24 & ASTM No.5 \\
slab & $200^{\circ} \mathrm{C}$ & 810 & 1110 & 25 & \\
& $300^{\circ} \mathrm{C}$ & 801 & 1084 & 25 & \\
& $400^{\circ} \mathrm{C}$ & 785 & 1010 & 25 & \\
& $500^{\circ} \mathrm{C}$ & 780 & 1000 & 25 & \\
& $600^{\circ} \mathrm{C}$ & 765 & 0987 & 25 & \\
& $650^{\circ} \mathrm{C}$ & 752 & 0955 & 24 & \\
& $700^{\circ} \mathrm{C}$ & 680 & 0832 & 18 & \\
& $750^{\circ} \mathrm{C}$ & 615 & 0712 & 11 & \\
& $800^{\circ} \mathrm{C}$ & 572 & 0620 & 21 & \\
& $900^{\circ} \mathrm{C}$ & 170 & 0200 & 87 & \\
\hline 6mm thick & $700^{\circ} \mathrm{C}$ & 785 & 883 & 17 & ASTM No.5 \& 6 \\
sheet & $800^{\circ} \mathrm{C}$ & 586 & 610 & 32 & \\
& $900^{\circ} \mathrm{C}$ & 160 & 195 & 54 & \\
\hline
\end{tabular}




\section{Conclusions}

The manufacturing route for all the three grades of Superalloys - Alloy 718 , Alloy 706 and modified 706 even through remains same, modified 706 is easy to manufacture than Alloy 718 and the ultimate tensile property is almost near to that of Alloy 718. It is easily cold workable than Alloy 718. It is less prone to segregation problems akin to super alloys. Alloys ability for creep and stress rupture applications is to be established. The role of micro addition of Vanadium is to be investigated, this will also help in understanding accidental additions in Ni-Cr-Fe type super alloy system. Further study on the alloy capability for oxidation resistance to be evaluated.

\section{References}

1. EE Brown and DR Muzyka, Nickel Iron Alloys" Superalloys - II, ed., CT Sims, NS Stoloff and W.C.Hagel. (New York, John welley \& Sons, 1987), Pages 165 - 188.

2. Inconel alloy 706 Technical bulletin, Special Metals Corporation SEPT., 2004

3. H 1 Eiselstein "Properties of Inconel Alloy 706" ASM Technical Report No. C 70.9.5 (1970) 1-21

4. E.L. Raymond and D.A.Wells "Effects of Aluminium content and Heat treatment on Gamma Prime struxcture and Yield strength of Inconel_Nickel chromium alloy 706 "superalloys ...... Processing Columbus, OH: MCIC, 1972, N1-N21.

5. F. Schuberf; H J PENKALLA, j. Rosler "Wrought Ni base alloys for Rotor Shafts in advanced USC Power Plants" proceedings from Forth International Conference on Advances in Materials Technology for fossil power plants, Oct 25 -28 , 2004 (587 - 601).

6. H. L. Eiselstein, "Metallurgy of a columbium hardened Nickel-Chromium-Iron Alloy" ASTM STP No. 369, (ASTM, Philadelphia, PA ,1965), 62-79.

7. G.D. Smith and S.J. Patel, "The Role of Niobium in Wrought Precipitation Hardened Nickel Base Alloys", Superalloys 718, 625, 706 and various Derivatives. TMS, 2005.

8. K.A. Heck, "The Time-Temperature-Transformation Behavior of Alloy 706" Superalloys 718, 625,706 and various Derivatives, TMS, 1994. 